\title{
EDITORIAL
}

\section{PHYSICAL FRAILTY: A BIOLOGICAL MARKER OF AGING?}

\author{
J.E. MORLEY
}

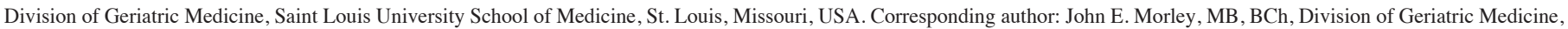

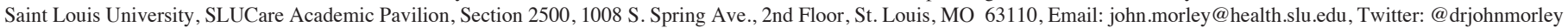

Key words: Physical frailty, biological marker, intrinsic capacity.

Intrinsic capacity is defined as the resilience that an individual has to overcome a variety of environmental, physical and psychological factors (1). A person's intrinsic capacity is created by their genes and a number of life style factors, e.g., exercise and diet, health care, e.g., vaccines and environmental. Intrinsic capacity tends to peak between 30 to 40 years, after which it slowly declines (2) (Figure 1). Frailty is defined when a person declines at a more rapid rate than that normally seen with the decline in age-related intrinsic capacity. Frail persons are at a greater risk of decline when exposed to stressors (3). In modern geriatrics frailty is interpreted as being a transitional process between a resident individual and one with disability $(4,5)$.

Physical frailty was operationalized by Fried et al (6). It was defined as fatigue, weight loss, weakness, slow walking gait and limited physical activity. It is predictive of poor outcomes when persons with disability are excluded (7). There are over 70 other definitions of frailty. The Rockwood Frailty Index is a co-morbidity index which can include disabilities and diseases (8). As such, it is more a marker of the effects of disease than a physiological marker of aging. Psychosocial frailty represents a separate form of frailty. Psychosocial frailty can represent a physiological decline, e.g., some forms of dementia or a disease process, such as depression, Lewy-Body dementia, and schizophrenia (9). Mild Cognitive Impairment (MCI) can be considered the equivalency of Fried's (6) definition of physical frailty. In many cases there is overlap between MCI and physical frailty (10-12).

Sarcopenia is a major component of physical frailty (13, 14). while loss of muscle mass and strength can be due to disease, e.g., diabetes mellitus or congestive heart failure much of sarcopenia is directly related to the aging process (primary sarcopenia) (13). A rapid screen for sarcopenia has been developed, i.e., the SARC-F (15-17).

Takeda et al (18) have suggested that both physical frailty and MCI, when not directly disease related, can be considered a clinical model for geroscience. Numerous senolytics and other age-delaying drugs are being developed in animal models (19). While most of these drugs are not yet ready for prime time, an exception is metformin which has been successfully used to treat diabetes mellitus (20). Epidemiological evidence strongly suggests that it delays the onset of dementia (21). Studies in mice support its use as a cognitive enhancer (22). Clinical studies are now ongoing looking at the effect of metformin as a retardant of the aging process (23). In addition, there is evidence that vaccinations such as influenza and diphtheria/ tetanus may lower the risk of dementia by modulating the T-cell immune response (24).

Numerous biomarkers for intrinsic capacity and aging phenotypes have been discovered $(25,26)$. These include nucleic acid-based, protein-based, metabolic-based and microbiome-based. Similarly, a number of biomarkers for physical frailty have been identified (26). A number of these overlap with aging biomarkers. Frailty has been shown to have a strong relationship to inflammatory cytokines (27-30). Progranulin is a highly conserved secreted protein that plays a role in inflammation, cell proliferation and cell repair (29). Progranulin is elevated in physical frailty $(25,30)$. Progranulin elevations are strongly related to elevated proinflammatory cytokines $(30,31)$. As such progranulin may be an excellent marker for physical frailty.

\section{Figure 1}

A schematic view of the decline of intrinsic capacity to physical frailty and disability over the lifespan

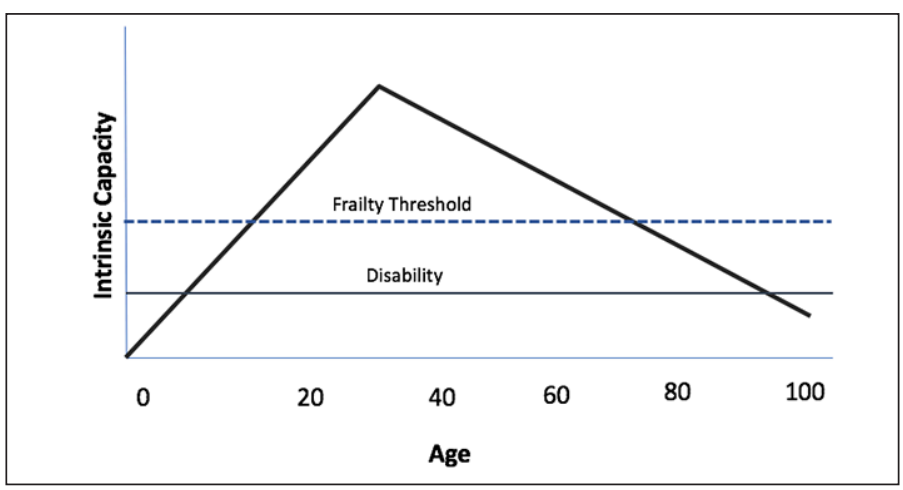

Early recognition of physical frailty and treatment may allow reversal of the aging process and restoration of resilience. Frailty can be rapidly recognized by the FRAIL questionnaire $(7,32,33)$. FRAIL is highly predictive of future disability and mortality (34). Physical frailty can be reversed in most cases with physical exercise (35-37). High fruit and vegetable diets 


\section{THE JOURNAL OF NUTRITION, HEALTH \& AGING}

protect against frailty $(38,39)$. An olive oil-based diet which is high in phenyls may reverse the activity of proinflammatory cytokines $(40,41)$. The diet should also include a leucine enriched essential amino acid supplement to enhance muscle strength (42). Finally, the FRAIL has an associated algorithm that will recognize possible treatable causes of frailty such as sleep apnea and depression as well as the reversible causes of age associated anorexia (43-45).

The management of aging associated factor needs to be patient centered (46). The early recognition of physical frailty in primary care practice, utilizing the FRAIL, is an excellent model for geroscience based secondary prevention. Future research will hopefully give us a number of biomarkers, such as progranulin, that will allow the development of individualized therapy for physical frailty. This will be particularly important in the combination of physical frailty and cognitive decline which tends to produce a more rapid overall decline (47-49).

Disclosures: The authors declare there are no conflicts

\section{References}

1. Beard JR, Jotheeswaran AT, Cesari M, de Carvalho IA. The structure and predictive value of intrinsic capacity in a longitudinal study of ageing. BMJ Open 2019;9:e26119. Doi: 10.1136/bmjopen-2018-026119.

2. Morley JE. Editorial: Geriatrics: Highlights of the last 50 years. J Nutr Health Aging 2019;23:910-913.

3. Dent E, Morley JE, Cruz-Jentoft AJ, et al. Physical frailty: ICFSR International clinical practice guidelines for identification and management. J Nutr Health Aging 2019;23:771-787

4. Dent E, Lien C, Lim WS, et al. The Asia-Pacific clinical guidelines for the management of frailty. J Am Med Dir Assoc 2017;18:564-575.

5. Morley JE, Vellas B, Abellan van Kan G, et al. Frailty consensus: A call to action. J Am Med Dir Assoc 2013;14:392-397.

6. Fried LP, Tangen CM, Walston J, et a; Cardiovascular Health Study Collaborative Research Group. Frailty in older adults: Evidence for a phenotype. J Gerontol A biol Sci Med Sci 2001;56:M146-M156.

7. Malmstrom TK, Miller DK, Morley JE. A comparison of four frailty models. J Am Geriatr Soci 2014;62:721-726.

8. Rockwood K, Song X, MacKnight C, et al A global clinical measure of fitness and frailty in elderly people. CMAJ 2005;175:489-495.

9. Morley JE. An overview of cognitive impairment. Clin Geriatr Med 2018;34:505 513.

10. Kelaiditi E, Cesari M, Canevelli M, et al. Cognitive frailty: Rational and definition from an (I.A.N.A./I.A.G.G.) international consensus group. J Nutr Health Aging 2013; $17: 726-734$

11. Kwan RYC, Leung AYM, Yee A, et al. Cognitive frailty and its association with nutrition and depression in community-dwelling older people.

12. Tseng SH, Liu LK, Peng LN, et al. Development and validation of a tool to screen for cognitive frailty among community-dwelling elders. J Nutr Health Aging 2019;23:904-909.

13. Morley JE, Sanford AM. Editorial: Screening for sarcopenia. J Nutr Health Aging 2019;23:768-770

14. Dent E, Morley JE, Cruz-Jentoft AJ, et al. International Clinical Practice Guidelines for Sarcopenia (ICFSR): Screening, diagnosis and management. J Nutr Health Aging 2018;22:1148-1161

15. Ha YC, Won Won C, Kim M, Chun KJ, Yoo JI. SARC-F as a useful tool for screening sarcopenia in elderly patients with hip fractures. J Nutr Health Aging 2020;24:78-82

16. Sanchez-Rodriguez D, Marco E, Davalos-Yerovi V, et al. Translation and validation of the Spanish version of the SARC-F questionnaire to assess sarcopenia in older people. J Nutr Health Aging 2019;23:518-524.

17. Malmstrom TK, Miller DK, Simonsick EM, et al. SARC-F: A symptom score to predict persons with sarcopenia at risk for poor functional outcomes. J Cachexia Sarcopenia Muscle 2016;7:28-36.

18. Takeda C, Angioni D, Setphan E, et al. Age-related frailty: A clinical model for geroscience? J Nutr Health Aging 2020;10.1007/s12603-020-1491-4.

19. Morley JE. Senolytics: The modern snake oil? J Nutr Health Aging 2019;23:490-493.

20. Morley JE, Perry HM 3rd. The management of diabetes mellitus in older individuals. Drugs 1991;41:548-565
21. Scherrer JF, Salas J, Floyd JS, et al. Metformin and sulfonylurea use and risk of incident dementia. Mayo Clin Proc 2019;94:1444-1456.

22. Farr SA, Roesler E, Niehoff ML, et al. Metformin improves learning and memory in the SAMP8 mouse model of Alzheimer's disease. J Alzheimers Dis 2019;68:1699. 1710 .

23. Kulkarni AS, Gubbi S, Barzilai N. Benefits of metformin in attenuating the hallmarks of aging. Cell Metab 2020;32:15-30.

24. Rivera-Segura NA, Bello-Chavolla OY, Barrera-Vazquez OS, et al. Promising biomarkers of human aging: In search of a multi-omics panel to understand the aging process from a multidimensional perspective. Ageing Research Reviews 2020 Sept. https://doi.org/10.1016/j.arr.2020.101164.

25. Verreault R, Laurin D, Lindsay J, de Serres G. Past exposure to vaccines and subsequent risk of Alzheimer's disease. CMAJ 2001;165:1495-1498.

26. Cardosa AL, Fernandes A, Aguilar-Pimentel JA, et al. Towards frailty biomarkers; candidates from genes and pathways regulated in aging and age-related diseases. Ageing Res Rev 2018;47:214-277

27. Marcos-Perez D, Sanchez-flores M, Proietti S, et al. Association of inflammatory mediators with frailty status in older adults: Results from a systematic review and meta-analysis. Geroscience. 2020; Aug 15. Doi: 10.1007/s11357-020-00247-4.

28. Morley JE. Developing novel therapeutic approaches to frailty. Curr Pharm Des 2009; 15:3384-3395.

29. Morley JE, Farr SA, Nguyen AD. Alzheimer disease. Clin Geriatr Med 2018;34:591 601

30. Leng SX, Xue QL, Tian J, Walston JD, Fried LP. Inflammation and frailty in older women. J Am Geriatr Soc 2007;55:864-871

31. Nguyen AD, Malmstrom TK, Niehoff ML, et al. Serum progranulin levels are associated with frailty in middle-aged individuals. PLoS One 2020;15:e0238877. Doi: 10.1371/journal.pone0238877. eCollection 2020.

32. Woo J, Leung J, Morley JE. Comparison of frailty indicators based on clinical phenotype and the multiple deficit approach in predicting mortality and physical limitation. J Am Geriatr Soc 2012;60:1478-1486.

33. Ma L. Current situation of frailty screening tools for older adults. J Nutr Health Aging 2019;23:111-118.

34. Aprahamian I, Arico de Almeida GV, de Vasconcellos Romanin CF, et al. Frailty could predict death in older adults after admission at Emergency department? A 6-month prospective study from a middle-income country. J Nutr Health Aging 2019;23:641-647.

35. Yu R, So MC, Tong C, Ho F, Woo J. Older adults' perspective towards participation in a multicomponent frailty prevention program: A qualitative study. J Nutr Health Aging 2020;24:758-764.

36. Huang $\mathrm{CH}$, Umegaki $\mathrm{H}$, Makinnno $\mathrm{T}$, et al. Effect of various exercises on frailty among older adults with subjective cognitive concerns: A randomized controlled trial Age Ageing 2020;Jun 10. DOI: 10.1093/ageing/afaa086 [Epub ahead of print]

37. Sadjapoing U, Yodkeeree S, Sungkarat S, Siviroj P. Multicomponent exercise program reduces frailty and inflammatory biomarkers and improves physical performance in community-dwelling older adults: A randomized controlled trial. Int J Environ Res Public Health 2020;17:3760. Doi: 10.3390/ijerph17113760.

38. Ribero SML, Morley JE, Malmstrom TK, Miller DK. Fruit and vegetable intake and physical activity as predictors of disability risk factors in African-American middleaged individuals. J Nutr Health Aging 2016;20:891-896.

39. Gao J, Jia Y, Dai J, et al. Association of fruit and vegetable intake and frailty among Chinese elders: A cross-sectional study in three cities. J Nutr Health Aging 2019;23:890-895.

40. Martinez-Lapiscina EH, Clavero P, Toledo E, et al. Virgin olive oil supplementation and long-term cognition: The PREDIMED-NAVARRA randomized, trial. J Nut Health Aging 2013;17:544-552.

41. Farr SA, Price TO, Domiguez LJ, et al. Extra virgin olive oil improves learning and memory in SAMP8 mice. J Alzheimers Dis 2012;28:81-92.

42. Bauer J, Morley JE, Schols AMWJ, et al. Sarcopenia: A time for action. An SCWD position paper. J Cachexia Sarcopenia Muscle 2019;10:956-961.

43. Morley JE. Rapid geriatric assessment: Secondary prevention to stop age-associated disability. Clin Geriatr Med 2017;33:431-440.

44. Morley JE. Frailty and sarcopenia: The new geriatrics giants. Rev Invest Clin 2016;68:59-67.

45. Jadczak AD, Visvanathan R. Anorexia of aging - an updated short review. J Nutr Health Aging 2019;23:306-309.

46. Morley JE, Vellas B. Patient-centered (P4) medicine and the older person. J AM Med Dir Assoc 2017;18:455-459.

47. Tarazona-Santabalbina FJ, Gomez-Cabrera MC, Perez-Ros P, et al. A multicomponent exercise intervention that reverses frailty and improves cognition, emotion, and social networking in the community-dwelling frail elderly: A randomized clinical trial. J Am Med Dir Assoc 2016;17:426-433.

48. Ge M, Zhang Y, Zhao W, et al. Prevalence and its associated factors of physical frailty and cognitive impairment: Findings from the West China Health and Aging Trend Study (WCHAT). J Nutr Health Aging 2020;24:525-533.

49. Ruan Q, Xiao F, Gong K, et al. Prevalence of cognitive frailty phenotypes and associated factors in a community-dwelling elderly population. J Nutr Health Aging 2020;24:172-180. 